investigación económica, vol. LXVIII, 268, abril-junio de 2009, pp. 15-38

\title{
A modified Kaldorian model of cumulative causation
}

José Luis da Costa Oreiro*

\section{INTRODUCTION}

Neoclassical growth models take for granted that the ultimate limit to long-run growth is the supply of factors of production (Solow, 1957). Aggregate demand is relevant only to determine the degree of productive capacity in the short-run, but has no lasting impact over the growth rate of productive capacity. In the long-run, Say's Law is valid, that is, supply determines demand.

However, supply of factors of production is not really independent of demand. The relation between the supply of production factors and aggregate demand was analyzed by Kaldor (1988), giving a new stimulus to the so-called demand-led growth theory. ${ }^{1}$ The starting point of the demand-

Received January 2008; accepted April 2008.

* Universidade de Brasília, <jlcoreiro@terra.com.br>. The author acknowledges the useful comments of Gary Dymski, Giulio Guarini, Mark Setterfield, Massimiliano la Marca, Thomas Palley and of the anonymous referees of Investigación Económica. Technical assistance of Breno P. Lemos for numerical simulation of the model is also recognized.

${ }^{1}$ We have to notice that the importance of aggregate demand for long-run growth was emphasized by other Keynesian authors before Kaldor. In the growth model of Joan Robinson (1962), for 
led growth models is that means of production used in a capitalist economy are themselves goods produced within the system. If that is so, the supply of means of production should never be considered as a datum independent of the demand for them. In this framework, the fundamental economic problem is not the allocation of a given quantity of resources over the possible alternatives; but the determination of the rate of growth of these resources. In the words of Setterfield:

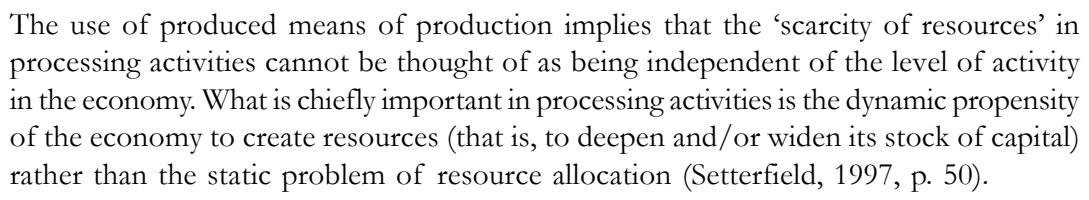

Kaldor's ideas about demand-led growth have been presented in formal models of cumulative causation where the rate of growth of output is determined by the growth rate of exports, which is determined by the growth rate of labor productivity (considering a fixed exchange-rate regime) induced by the growth rate of real output. ${ }^{2}$ In this setting, it is possible to construct dynamic models where initial conditions largely determine the long-run growth rate. ${ }^{3}$

Kaldorian cumulative causation models, as the one developed by Setterfield (1997), have four equations: a first equation where the growth

example, the growth rate of capital stock is determined by the interplay between the propensity to invest of capitalists (determined by their animal spirits) and the propensity to save out of profits. An increase in the propensity to save out of profits will produce a reduction in the desired rate of accumulation, showing the fundamental importance of aggregate demand for long-run growth. However, it remains the idea that the availability of means of production sets an upper limit for long-run growth. In fact, the growth rate of the labor force is considered an exogenous variable in the system and can set an upper limit to economic growth since the economy could not grow indefinitely at a rate bigger than the one allowed by the expansion of the labor force (adjusted by technical progress). In a 1988 article, Kaldor argued that, in the long-run, the growth rate of labor force is not independent of demand, but adjusts itself to the growth of demand for labor.

${ }^{2}$ Some empirical evidences about the validity of these classes of models is obtained in Ledesma and Thirlwall (2002).

${ }^{3}$ See Dixon and Thirlwall (1975) and Setterfield (1997). 
rate of real output is a function of the growth rate of exports; a second equation in which the growth rate of exports is a function of the rate of change of terms of trade and of the growth rate of world's income; a third equation that specifies the productivity growth rate as a function of the growth rate of real output (a simple formalization of Kaldor-Verdoorn Law); and a fourth equation where the rate of change of domestic prices is determined by the rate of change in nominal wages, the growth rate of productivity and the rate of change of nominal exchange-rate. It is also assumed the existence of a fixed-exchange rate regime and/or that priceelasticity of exports is zero.

Up to now, no effort has been done in order to incorporate to these dynamic models some important aspects of open-economy macroeconomics as, for example, the openness of capital account and the existence of a floating exchange-rate regime. Furthermore, Kaldorian models of cumulative causation completely ignore the effects of monetary policy over long-run growth, what is a surprising feature, given the obvious Keynesian background of this class of growth models.

The objective of this article is to present a dynamic model of demandled growth in order to analyze the effects of changes in monetary policy rules and in the degree of openness in the capital account over the timepath of the growth rate of real output, the nominal interest rate and the rate of inflation.

The model to be presented here is an original contribution to the Post Keynesian theory of growth because: i) it combines in one dynamic model a set of Keynesian assumptions about the nature of the growth process presented by different models of economic growth in the Post Keynesian tradition; ${ }^{4}$ and ii) it also integrates monetary policy rules and international capital

\footnotetext{
${ }^{4}$ The Keynesian assumptions about the nature of the growth process that are incorporated in the model are: i) the key role of autonomous demand, mainly growth of exports, for long-run growth; ii) the endogenous nature of technical progress as expressed by the "Kaldor-Verdoorn law"; iii) the dual nature of investment as a component of effective demand and as the determinant of productive capacity; and iv) the importance of the principle of acceleration as well as the real interest rate to the determination of investment expenditures.
} 
markets within the formal structure of a Post Keynesian growth model, allowing for the analysis of changes in the monetary policy rules and/or in the degree of openness of capital account over the long-run growth.

The main theoretical result of the model to be presented here is the role of inflation for the existence of a balanced growth path. In fact, a balanced growth path -i.e. a dynamic path where output and productive capacity grow at the same rate in the long run- requires that the rate of inflation must assume a definite value in the long-run. So the compatibility of inflation targeting and balanced growth requires that the Central Bank must set the long-run inflation target equal to the value of the inflation rate that generate a balanced growth, which is the so-called "balanced growth rate of inflation".

Another interesting and original result of the model presented here is the idea that a flexible inflation targeting is required for a balanced growth. Although some Post Keynesian economists argue that inflation targeting is per se incompatible with Post Keynesian economics (Arestis and Sawyer, 2005, 2006; Davidson, 2006), our model suggests that in an economy that works according to Post-Keynesian principles, monetary policy could be guided by inflation targeting if the long-run target for inflation is flexible enough to being adjusted to changes in the balanced growth rate of inflation that are produced by changes in the international rate of interest and/or the growth rate of world's income. Flexibility in the setting of the target for inflation is all that is necessary for an inflation targeting regime to be compatible with Post Keynesian economics.

The model also reproduces some results that are common knowledge in Post Keysesian growth theory. In particular, our model shows that: i) longrun growth could be promoted by some form of industrial policy; ii) high interest rates promote macroeconomic instability; and iii) financial liberalization and capital account convertibility do not have any significant impact over long-run growth.

The present article is organized in five sections, including the introduction. In the second section we show the theoretical structure of the modified Kaldorian cumulative causation model, assuming the degree 
of productive specialization as given and independent from the real exchange-rate. In the third section we show the steady-state solution of the model at hand. Fourth section is dedicated to the numerical simulation of the model presented in the second section. The last section presents final remarks and conclusions obtained in the paper.

\section{THE STRUCTURE OF THE THEORETICAL MODEL}

The model presented here is an extension of the Kaldorian model of cumulative causation developed by Setterfield (1997). It is well known that the standard model of cumulative causation has four dynamic equations: a first equation relating the growth rate of labor productivity with the growth rate of real output (the so-called "Kaldor-Verdoorn Law"), a second equation presenting the rate of inflation as the difference between the rate of increase in nominal wages and the growth rate of labor productivity, a third equation showing the growth rate of exports as a function of the evolution of price-competitiveness of exports and the growth rate of world's income and a fourth equation showing the growth rate of real output as a function of the growth rate of exports.

In our model we will introduce some modifications to the basic structure of the standard Kaldorian cumulative causation model. First of all, as suggested by Palley (2002), we will add two new equations to the standard model with the purpose of analyzing the dynamics of the productive capacity of the economy. In fact, standard models of cumulative causation say nothing about the supply side of the economy, that is, about the evolution of productive capacity through time. This omission will be solved by means of adding a dynamic equation relating the growth rate of productive capacity with the investment rate, in a fashion similar to Domar (1946). The second equation to be introduced is an investment function in which the investment rate at time $t$ is a function of the lagged growth rate of real output -in accordance with the accelerator model of investment behavior- and of the lagged real interest rate. Secondly, we assume that the rate of change of nominal wages is not uniform in the world economy 
(Setterfield, 1997, p. 55), but country-specific; domestic labor unions can manage to fix the rate of change in nominal wages at a pace equal to the inflation rate of the last period plus productivity gains occurred in the last period. Third, we will suppose an economy that operates under a floating exchange-rate regime in a setting of restricted (imperfect) capital mobility due to the presence of some form of capital controls. In this framework, the rate of change of nominal exchange-rate is supposed to be a linear function of the difference between the domestic nominal interest rate and the international nominal interest rate adjusted by the country-risk premium. Because of that, the interest rate differential will have an impact over the domestic rate of inflation (by means of exchange-rate variations) and overt the price-competitiveness of exports, opening a channel by which monetary policy can have an influence over long-run growth rate. Finally, we will assume that monetary policy is conducted under the institutional framework of an inflation targeting regime, and the Central Bank sets nominal interest rates at each period based on a version of the so-called "Taylor rule".

The structure of the can be presented as follows:

$$
\begin{gathered}
\hat{q}_{t}=r+\alpha \hat{Y}_{t-1} \\
\hat{\bar{Y}}_{t}=\sigma \frac{I_{t-1}}{Y_{t-1}} \\
\frac{I_{t}}{Y_{t}}=\varphi_{1} \hat{Y}_{t-1}+\varphi_{2}\left(i_{t-1}-\hat{p}_{t-1}\right) \\
\hat{p}_{t}=\hat{w}_{t}+\hat{e}_{t}-\hat{q}_{t} \\
\hat{w}_{t}=\hat{p}_{t-1}+\hat{q}_{t-1} \\
\hat{X}_{t}=\beta\left(\hat{p}_{w, t}+\hat{e}_{t}-\hat{p}_{t}\right)+\gamma \hat{Y}_{w, t}
\end{gathered}
$$




$$
\begin{gathered}
\hat{Y}_{t}=\lambda \hat{X}_{t} \\
\hat{e}_{t}=\vartheta\left(i_{t}-i_{t}^{*}-\rho\right) \\
i_{t}^{d}=\left(i_{t}^{*}+\rho\right)+\theta_{1}\left(\hat{p}_{t-1}-\pi_{t}^{*}\right)+\theta_{2}\left(\hat{Y}_{t-1}-\hat{\bar{Y}}_{t-1}\right) \\
i_{t}=\theta_{0} i_{t}^{d}+\left(1-\theta_{0}\right) i_{t-1} \\
\pi_{t}^{*}=\omega \pi_{t-1}^{*}+(1-\omega) \pi_{L P}
\end{gathered}
$$

Where: $\hat{q}_{t}$ is the growth rate of labor productivity in period $t, \hat{Y}_{t}$ is the growth rate of real output, $\hat{\bar{Y}}_{t}$ is the growth rate of productive capacity in period $t$, $I_{t}$ is planed investment in period $t, \hat{p}_{t}$ is the rate of inflation in period $t, \hat{w}_{t}$ is the rate of change in nominal wages in period $t, \hat{e}_{t}$ is the rate of change in nominal exchange rate in period $t, \hat{p}_{w, t}$ is the rate of inflation in the rest of the world economy in period $t, \hat{Y}_{w, t}$ is the rate of growth of world's income in period $t, \hat{X}_{t}$ is the growth rate of exports in period $t, \rho$ is the country's risk premium; $i_{t}$ is the nominal interest rate set by the Central Bank in period $t, i_{t}^{d}$ is the nominal interest rate target for period $t, \pi_{t}^{*}$ is the target inflation for period $t$ and $\pi_{L P}$ is the long-run target for inflation rate. The constants $r, \alpha, \sigma, \beta, \gamma, \lambda, \theta_{0}, \theta_{1}, \theta_{2}, \varphi_{1}$ y $\omega$ are all positive, but $\varphi_{2}$ and $\vartheta$ are negative.

Equation [1] represents the Kaldor-Verdoorn Law, according to which the growth rate of labor productivity is a positive function of the growth rate of real output due to the existence of static and dynamic economies of scale.

Equation [2] presents the growth rate of productive capacity in period $t$ as a function of the rate of investment of period $t-1$. In this setting, the coefficient $\sigma$ must be understood -as in Domar (1946) - as the social productivity of investment, that is, as a coefficient that determines the increase in productive capacity or in potential output that results from an increase in the level of realized investment expenditures.

Equation [3] shows the rate of investment that is desired by entrepreneurs for period $t$ as a function of the growth rate of output in period $t-1$ and 
real interest rate in period $t-1$. This specification of the investment function combines the "principle of acceleration" (Harrod, 1939) with the Keynesian theory of the marginal efficiency of capital (Keynes, 1936, ch.11) according to which desired investment is a negative function of the rate of interest.

Equation [4] shows the rate of inflation in period $t$ as being equal to the rate of change in nominal wages plus the rate of change of nominal exchange-rate minus the rate of growth of labor productivity.

Equation [5] shows the rate of change of nominal wages as equal to the sum of the rate of inflation in period $t-1$ and the growth rate of productivity. Labor unions follow a very simple rule for wage bargains: the rate of change of nominal wages must be high enough to compensate loses of purchasing power due to inflation and to incorporate all productivity gains to real wages.

Equation [6] represents the growth rate of exports as a function of the rate of change of real the exchange-rate (by definition, equals to rate of change of nominal exchange rate plus the international rate of inflation minus the domestic rate of inflation) and of the rate of growth of world's real income. We must emphasize that $\gamma$ is the income-elasticity of exports.

Equation [7] shows the growth rate of real output as a function of the growth rate of exports. In this setting, coefficient $\lambda$ must be understood as the non-resident autonomous expenditure (exports) multiplier.

Equation [8] shows the rate of change in nominal exchange-rate as a linear function of the difference between domestic nominal interest rate and the international nominal interest rates adjusted by the country's risk premium. So we are considering an economy where a floating exchange rate regime prevails in a context of restricted capital mobility due to the existence of some form of capital controls.

Equations [9] and [9a] represent the monetary policy rule adopted by the Central Bank. In equation [9] we can see that the nominal interest rate set by the Central Bank in period $t$ depends on three determinants. The first one is the long-run equilibrium value for the nominal interest rate, given by the sum of international interest rates and the risk-premium. The second component is the difference between the actual rate of inflation and the 
target rate of inflation for period $t$. The third determinant is the difference between the actual growth rate of real output and the growth rate of productive capacity. In this setting, we assume that the Central Bank will change the nominal interest rate relative to its equilibrium value in order to achieve two policy objectives: to keep inflation in line with target inflation for that period and to minimize the gap between the actual growth rate of real output and the growth rate of productive capacity.

Equation [9a] shows that the Central Bank adjusts slowly the actual value of the nominal interest rate to its desired value, determined by equation [9]. This equation is a simple formalization of the stylized fact about the behavior of the Central Banks in the operation of monetary policy, according to which Central Banks try to avoid sudden changes in nominal interest rates in order to minimize interest-rate volatility (Barbosa, 2004, p. 105).

Finally, equation [10] shows that the inflation target for period $t$ is a weighted average of the rate of target inflation for period $t-1$ and the long-run inflation target. We assume that Central Bank operates its monetary policy with a view to induce a gradual convergence of actual inflation with the long-run inflation target, defined in an exogenous way.

Once we have specified the structure of the model, it can be presented in a reduced form. After putting equations [1], [5] and [8] in [4] we arrive at the following expression:

$$
\hat{p}_{t}=\hat{p}_{t-1}-\alpha\left(\hat{Y}_{t-1}-\hat{Y}_{t-2}\right)+\vartheta\left(i_{t}-i_{t}^{*}-\rho\right)
$$

In equation [11] the rate of inflation in period $t$ is a function of the last period's rate of inflation, so that there is a strong degree of inflation inertia in this economy. Besides that, growth acceleration between $t-1$ and $t-2$ is associated with a reduction in the rate of inflation. This surprising result is due to the effects of growth acceleration over the growth rate of productivity, which causes a reduction of the rate of inflation. Finally, monetary policy affects inflation through the exchange rate channel, which appears to be in accordance with the empirical evidence for emergent economies. 
Getting [8] in [6] and the resulting equation in [7] we arrive at the following expression:

$$
\hat{Y}_{t}=\lambda \beta \alpha\left(\hat{Y}_{t-1}-\hat{Y}_{t-2}\right)+\lambda \gamma \hat{Y}_{t, w}+\lambda \beta\left(\hat{p}_{w, t}-\hat{p}_{t-1}\right)
$$

Equation [12] shows that:

1. Growth acceleration between $t-1$ and $t-2$ will have a positive impact over the growth rate of real output in period $t$.

2. An increase in the growth rate of world's income will increase the rate of growth of real output.

3. A reduction in the rate of inflation relative to the international level will increase the growth rate of real output.

Lagging [3] one period and getting the resulting expression in [2], we arrive at the following equation:

$$
\hat{\bar{Y}}_{t}=\sigma\left(\varphi_{1} \hat{Y}_{t-2}+\varphi_{2}\left(i_{t-2}-\hat{p}_{t-2}\right)\right)
$$

Based on [13] we can conclude that the rate of growth of productive capacity is a function of the growth rate of real output in period $t-2$ and of the level of real interest rate for that period.

Getting [9] in [9a], we arrive at the following expression:

$$
i_{t}=\left(1-\theta_{0}\right) i_{t-1}+\theta_{0}\left(i_{t}^{*}+\rho\right)+\theta_{0} \theta_{1}\left(\hat{p}_{t-1}-\pi_{t}^{*}\right)+\theta_{0} \theta_{2}\left(\hat{Y}_{t-1}-\hat{\bar{Y}}_{t-1}\right)
$$

Equation [9b] shows that the nominal interest rate set by the Central Bank in period $t$ depends on the level of the nominal interest rate in period $t-1$ (interest rate inertia), the level of nominal interest rates of the rest of the world adjusted by the risk-premium, the difference between the rate of inflation in period $t-1$ and the inflation target for period $t$ and the difference between the growth rate of real output in the previous period and the growth rate of productive capacity. 
The reduced form of the model presented so far is given by the following system of equations:

$$
\begin{gathered}
i_{t}=\left(1-\theta_{0}\right) i_{t-1}+\theta_{0}\left(i_{t}^{*}+\rho\right)+\theta_{0} \theta_{1}\left(\hat{p}_{t-1}-\pi_{t}^{*}\right)+\theta_{0} \theta_{2}\left(\hat{Y}_{t-1}-\hat{\bar{Y}}_{t-1}\right) \\
\pi_{t}^{*}=\omega \pi_{t-1}^{*}+(1-\omega) \pi_{L P} \\
\hat{p}_{t}=\hat{p}_{t-1}-\alpha\left(\hat{Y}_{t-1}-\hat{Y}_{t-2}\right)+\vartheta\left(i_{t}-i_{t}^{*}-\rho\right) \\
\hat{Y}_{t}=\lambda \beta \alpha\left(\hat{Y}_{t-1}-\hat{Y}_{t-2}\right)+\lambda \gamma \hat{Y}_{t, w}+\lambda \beta\left(\hat{p}_{w, t}-\hat{p}_{t-1}\right) \\
\hat{\bar{Y}}_{t}=\sigma\left(\varphi_{1} \hat{Y}_{t-2}+\varphi_{2}\left(i_{t-2}-\hat{p}_{t-2}\right)\right)
\end{gathered}
$$

\section{THE STEADY-STATE EQUILIBRIUM OF THE MODEL}

The steady-state solution for the model presented by equations [9b]-[13] is such that $\hat{p}_{t}=\hat{p}_{t-1}=\hat{p} ; \hat{Y}_{t}=\hat{Y}_{t-1}=\hat{Y}$ and $\pi_{t}^{*}=\pi_{t-1}^{*}=\pi_{L P}$ [14]. Getting [14] in [11], we arrive at the following expression: ${ }^{5}$

$$
i=i^{*}+\rho
$$

The long-run equilibrium value of the nominal interest rate is equal to the sum of the world's nominal interest rate and the risk-premium. In the longrun, the nominal rate of interest is independent of monetary policy.

From [12], we get:

\footnotetext{
${ }^{5}$ In what follows we will suppose that the international rate of inflation, the growth rate of world's income and risk-premium are constant through time.
} 


$$
\hat{Y}=\lambda \gamma \hat{Y}_{w}+\lambda \beta\left(\hat{p}_{w}-\hat{p}\right)
$$

Equation [*] shows the long-run equilibrium value for the growth rate of real output. Clearly, the long-run growth rate of output depends on two factors: the growth rate of world's income and the difference between the level of inflation in the rest of the world and the domestic rate of inflation. In this framework, money is not super-neutral, since changes in the rate of inflation (relative to the international level) have a persistent effect over the growth rate of real output. Since the relation between inflation and growth is negative, monetary policy will promote a robust long-run growth if and only if it keeps inflation at low levels in comparison with the level prevailing in the rest of the world.

From [9b] we get:

$$
\hat{p}=\pi_{L P}-\left(\frac{\theta_{2}}{\theta_{1}}\right)(\hat{Y}-\hat{\bar{Y}})
$$

Based on $\left.{ }^{* *}\right]$, we observe that the long-run equilibrium rate of inflation will be equal to the long-run inflation target if and only if real output and productive capacity are growing at the same rate.

In order to determine if inflation will converge to its long-run target, we have first to calculate the expression for $(\hat{Y}-\hat{\bar{Y}})$. Getting $\left.{ }^{*}\right]$ in [13] we obtain:

$$
\hat{\bar{Y}}=\sigma \varphi_{1}\left[\lambda \gamma \hat{Y}_{w}+\lambda \beta\left(\hat{p}_{w}-\hat{p}\right)\right]+\sigma \varphi_{2}(i-\hat{p})
$$

Subtracting $\left[{ }^{*}\right]$ from $\left[{ }^{* *}\right]$, we arrive at the following expression:

$$
\hat{Y}-\hat{\bar{Y}}=\left(1-\sigma \varphi_{1}\right) \lambda\left[\gamma \hat{Y}_{w}+\beta\left(\hat{p}_{w}-\hat{p}\right)\right]-\sigma \varphi_{2}(i-\hat{p})
$$

Getting [16] in [**], we arrive at: 


$$
\begin{gathered}
\hat{p}=\frac{\theta_{1}}{\theta_{1}+\theta_{2}\left[\sigma \varphi_{2}-\left(1-\sigma \varphi_{1}\right) \lambda \beta\right]} \pi_{L P} \\
-\frac{\theta_{1} \theta_{2}}{\theta_{1}\left\{\theta_{1}+\theta_{2}\left[\sigma \varphi_{2}-\left(1-\sigma \varphi_{1}\right) \lambda \beta\right]\right\}}\left[\left(1-\sigma \varphi_{1}\right) \lambda\left(\gamma \hat{Y}_{w}+\beta \hat{p}_{w}\right)-\sigma \varphi_{2}\left(i^{*}+\rho\right)\right]
\end{gathered}
$$

In equation [17] we observe that, in general, the long-run equilibrium rate of inflation is different from its long-run target. Convergence will only occur if $\theta_{2}=0$; i.e., the weight of differences between growth rates of real output and productive capacity in Taylor's rule must be set equal to zero. This result is a natural consequence of the Tinbergen's Economic Policy Theorem, according to which there must be equality between the number of policy goals and the number of policy instruments. Since, in the model at hand, the Central Bank has only one instrument of monetary policy -the nominal interest rate- there must be only one goal for monetary policy: to control the rate of inflation.

Considering the fulfillment of the sufficiency condition for convergence of inflation to its long-run target, we must now turn our attention to the analysis of the behavior of the gap between the growth rate of real output and the growth rate of productive capacity. A balanced growth path requires the equality between both rates in order to guarantee a constant rate of capacity utilization in the long-run.

Subtracting [15] and [16] in [17] we get the long-run equilibrium value of the gap between growth rate of real output and the growth rate of productive capacity, which is given by the following expression:

$$
\hat{Y}-\hat{\bar{Y}}=\left(1-\sigma \varphi_{1}\right) \lambda\left[\gamma \hat{Y}_{w}+\beta \hat{p}_{w}\right]-\sigma \varphi_{2}\left(i^{*}+\rho\right)+\left[\sigma \varphi_{2}-\left(1-\sigma \varphi_{1}\right) \lambda \beta\right] \pi_{L P}
$$

The first two terms on the right-hand side of [19] are both positives, ${ }^{6}$ but the third term is negative, so the long-run equilibrium value of the gap must

${ }^{6}$ Considering $1>\sigma \varphi_{1}$. 
be positive or negative. However, the gap between the two rates is a function of the value of the long-run inflation target. The Central Bank can set the value for the long-run in order to guarantee the equality between the growth rate of real output and the growth rate of productive capacity. In this setting, we can define the balanced growth rate of inflation (BGRI) as the inflation rate that guarantees the equality between the growth rate of real output and the growth rate of productive capacity. ${ }^{7}$ The BGRI $\left(\pi_{L P}^{*}\right)$ is determined by the following expression:

$$
\pi_{L P}^{*}=\frac{\sigma \varphi_{2}\left(i^{*}+\rho\right)-\left(1-\sigma \varphi_{1}\right) \lambda\left[\gamma \hat{Y}_{w}+\beta \hat{p}_{w}\right]}{\left[\sigma \varphi_{2}-\left(1-\sigma \varphi_{1}\right) \lambda \beta\right]}
$$

In equation [19] BGRI is a function of the international rate of interest, the growth rate of world's income and the international rate of inflation. From this reasoning, we conclude that BGRI has to be set taking in consideration the conditions prevailing in the world economy, or otherwise the long-run target could be set at a level too high or too low for a balanced growth path to exist.

In sum, the analysis of the steady-state solution of the model at hand allowed us to reach the following conclusions:

- There is an inverse relation between the growth rate of real output and the rate of inflation, given the growth rate of world's income and the international rate of inflation.

\footnotetext{
${ }^{7}$ This concept has some similarities with the Minimum Unemployment Rate of Inflation developed by Palley (2006). According to him, the existence of a backward bending Phillips curve for low inflation levels guarantees the existence of a rate of inflation that minimizes the rate of unemployment. Central Banks, operating in a context of inflation targeting, must then set nominal interest rates in order to achieve this rate of inflation. In our model, the problem is not to achieve the minimum unemployment, but to achieve the highest possible growth rate for real output that is sustainable in the long-run. This requires the equality between the growth rate of real output and the growth rate of productive capacity. The long-run target for inflation must be set in a level such that the differences between both rates are zero.
} 
- The convergence of inflation rate to its long-run target requires that the Central Bank has only one goal for monetary policy: to control inflation. This is equivalent to set a weight equal to zero for the gap between the growth rate of real output and the growth rate of productive capacity in the interest rate rule.

- A balanced growth path requires that the Central Bank sets a long-run target for inflation that is flexible and adjustable to the conditions prevailing in the world economy. In particular, the long-run inflation target must be increased in periods of increasing levels of international interest rates and/or decreasing growth rates of the world economy.

\section{NUMERICAL SIMULATION OF THE THEORETICAL MODEL}

Once we have presented the properties of the balanced growth path of the economy, we must proceed to a numerical analysis of the dynamic paths for the economy in order to analyze the impact over these paths of changes in the parameters of the model that reflect changes in the rules of operation of monetary policy and/or the level of capital controls.

For the numerical simulation of the model we will consider the following values for the parameters and initial conditions of the system.

\section{TABLE 1}

Numerical values used in the standard simulation of the theoretical model

\begin{tabular}{lccc}
\hline Parameters & & \multicolumn{2}{c}{ Initial conditions (growth rates) } \\
\hline Alpha & 0.1 & Pt-1 & 0.03 \\
Epsilon & -0.25 & Yt-1 & 0.035 \\
Beta & 1.1 & Yt-2 & 0.021 \\
Gamma & 0.5 & Y0t-1 & 0.04 \\
Phi_2 & -0.1 & Rho & 0.01 \\
Lambda & 0.75 & Pw & 0.025 \\
Sigma & 0.5 & Yw & 0.04 \\
Phi & 2 & Pit-1 & 0.04 \\
Theta_0 & 0.1 & piLP & 0.03 \\
Theta_1 & 0.5 & iw & 0.02 \\
Theta_2 & 0.3 & it_1 & 0.05 \\
Omega & 0.75 & & \\
\hline
\end{tabular}


Some of these values are based on stylized facts about the long-run dynamic behavior of capitalist economies. For example, we are assuming a value for the social productivity of investment $(\sigma)$ equal to 0.5 . Since the capitaloutput ratio is equal to $(1 / \sigma)$, then a value for $\sigma$ equal to 0.5 means a capital-output ratio of 2 , what seems to be in accordance with the values found for this variable in many developed capitalist economies (Maddison, 1991). Also a long-run inflation target of 3\% per year seems to be in accordance with the experience of inflation targeting countries. Finally, a growth rate for the world economy of $4 \%$ per year and an inflation rate at $2.5 \%$ per year for the rest of the world seem to be very plausible estimates for the long-run values of these variables.

The dynamics of the growth rate of real output and productive capacity, inflation and nominal interest rates can be seen by means of figure 1 below:

\section{FigURE 1}

Dynamics of the growth rate of real output and productive capacity, inflation and nominal interest rate in the standard simulation

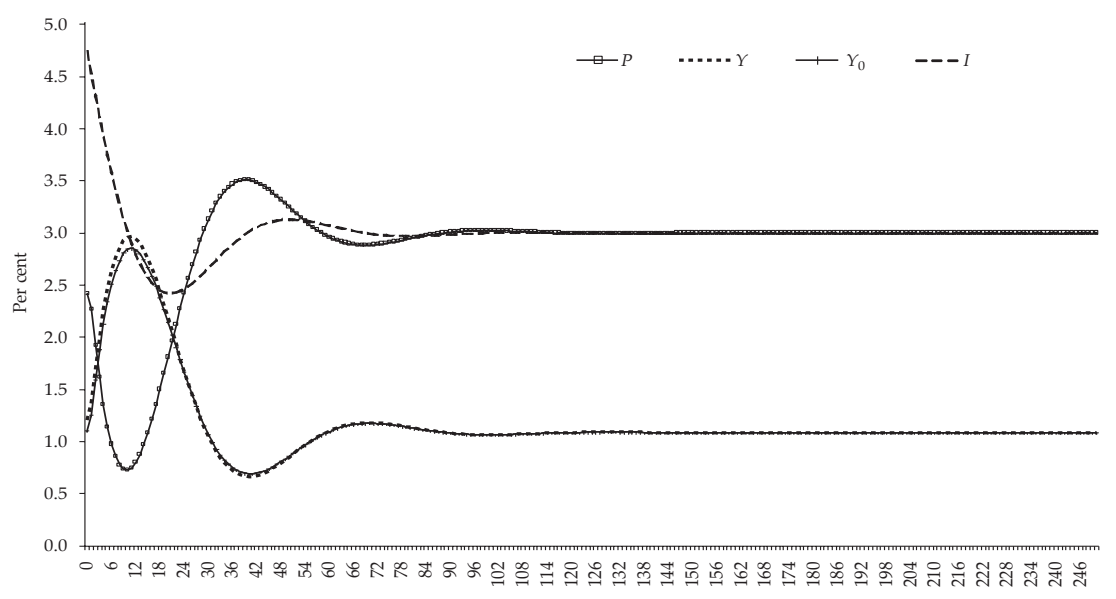

Where: $P$ is the rate of inflation, $Y$ is the growth rate of real output, $Y_{0}$ is the growth rate of productive capacity and $I$ is the short-run nominal interest rate. 
In the figure 1 above we can see that, for the values considered in the standard simulation, the selected variables converge to their long-run equilibrium values. So the model exhibits a stable dynamics for the selected values of structural parameters. In fact, the nominal interest rate converges to its steady-state value of $3 \%$ per year, given by the sum of the international interest rate $(2 \%$ per year) and the risk premium ( $1 \%$ per year). We can see also the convergence of the inflation rate to its long-run target of $3 \%$ per year.

The growth rate of real output shows damped oscillations around its longrun equilibrium value of $1 \%$ per year. This low value for the long-run growth rate is the consequence of a low income-elasticity of exports -set equal to 0.5 in the standard simulation-and of a low value for the exports multiplier -set equal to 0.75 in the standard simulation-. This low value for the exports multiplier is supposed to be the consequence of a high value for the incomeelasticity of imports. The combination of a low income-elasticity of exports with a high income-elasticity of exports allows us to conclude that there is a very high level of productive specialization, what has negative effects over the growth rate of exports and real output (Dosi et al., 1990).

Finally, the growth rate of productive capacity has a very similar behavior to that of real output. This fact is a simple consequence of the demandled nature of growth of the economy under analysis, in which growth of productive capacity adjusts itself to growth of demand and output.

We will now depart from the standard simulation in order to conduct two kinds of experiments. The first one will be testing the impact over the dynamics of the system of changes in the structural parameters of the economy, that is, in the parameters that reflect the level of productive specialization of the economy. The second one will be testing the impact over the system dynamics of a change in policy parameters, that is, parameters that represent the monetary policy and the level of capital controls. The objective of these experiments is to evaluate the contribution of monetary policy and industrial policy for the promotion of a robust growth in the long-run, considering the existence of a demand-led growth regime.

In the first experiment we will consider an increase in the income-elasticity of exports from 0.5 to 0.8 , reflecting the adoption of an industrial policy 
concerned with the reduction in the level of productive specialization of the economy at hand. The dynamics of the selected variables can be seen in figure 2 below:

\section{FIGURE 2}

Dynamics of the growth rate of real output and productive capacity, inflation and nominal interest rate considering a once-and-for all increase in the income elasticity of exports

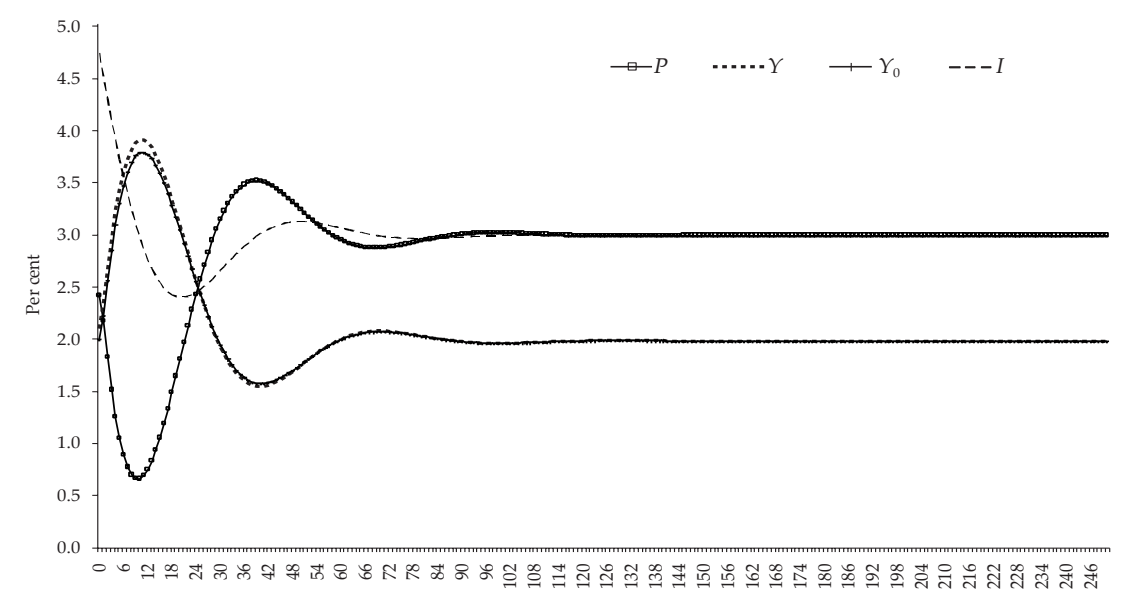

Where: $P$ is the rate of inflation, $Y$ is the growth rate of real output, $Y_{0}$ is the growth rate of productive capacity and $I$ is the short-run nominal interest rate.

An increase in the income elasticity of exports has a clear effect over the long-run equilibrium value for the growth rate of real output. In fact, as we can see in figure 2 , the growth rate of real output converges to a value of $2.0 \%$ per year, a $100 \%$ increase of the value observed in the standard simulation. The same effect can be observed for the growth rate of productive capacity. However, the dynamics of the nominal interest rate and the inflation rate does not change at all. Industrial policy has a strong effect over long-run growth, but seems to have no consequence for the conduct of monetary policy. 
In the second exercise we will consider an increase in the degree of interest rate smoothing by the Central Bank, that is, an increase in the coefficient that reflects the degree of interest-rate inertia in the economy at hand. ${ }^{8}$ For such, we will suppose that $\theta_{0}$ will be reduced from 0.1 to 0.05 . The dynamics of the selected variables is shown in figure 3 below:

\section{Figure 3}

Dynamics of the growth rate of real output and productive capacity, inflation and nominal interest rate considering an increase in the incomeelasticity of exports and in the level of interest-rate inertia

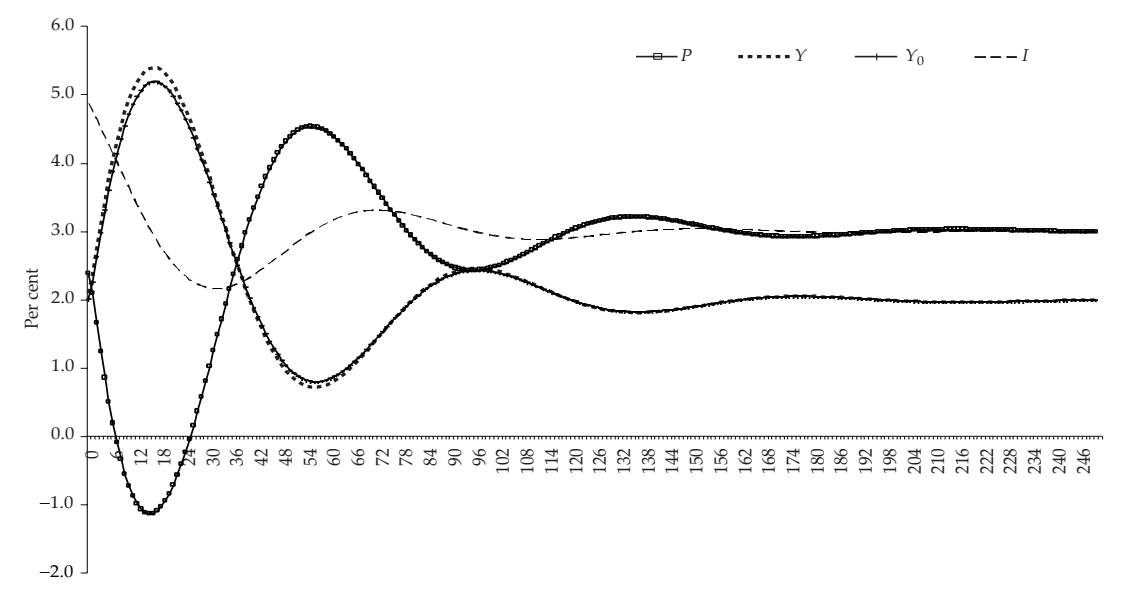

Where: $P$ is the rate of inflation, $Y$ is the growth rate of real output, $Y_{0}$ is the growth rate of productive capacity and $I$ is the short-run nominal interest rate.

In figure 3 we can see two things. First of all, an increase in the interest-rate inertia has no effects over the long-run values of the growth rate of real output, productive capacity, inflation and nominal interest rates. So the degree of conservatism in the conduct of monetary policy is irrelevant for the long-

\footnotetext{
${ }^{8}$ In this second exercise, we will take the same value of the income-elasticity of exports used in the first exercise.
} 
run dynamics of the economy at hand. However, an increase in the interestrate inertia has increased the amplitude of oscillations of the variables around their long-run equilibrium values. From this exercise we can conclude that the higher the degree of conservatism in the operation of monetary policy by the Central Bank, the bigger the macroeconomic instability.

In the third experiment we will consider a decrease in the level of capital controls, so that the sensibility of the rate of change of nominal exchange rate to interest rate differential will increase. ${ }^{9}$ More specifically, we will increase the value of $\varepsilon$ from -0.25 to -0.75 . The impact of this change over the dynamics of the selected variables is shown in figure 4 below:

\section{FIGURE 4}

Dynamics of the growth rate of real output and productive capacity, inflation and nominal interest rate assuming an increase in the incomeelasticity of exports and in the level of interest-rate inertia and a decrease in the level of capital controls

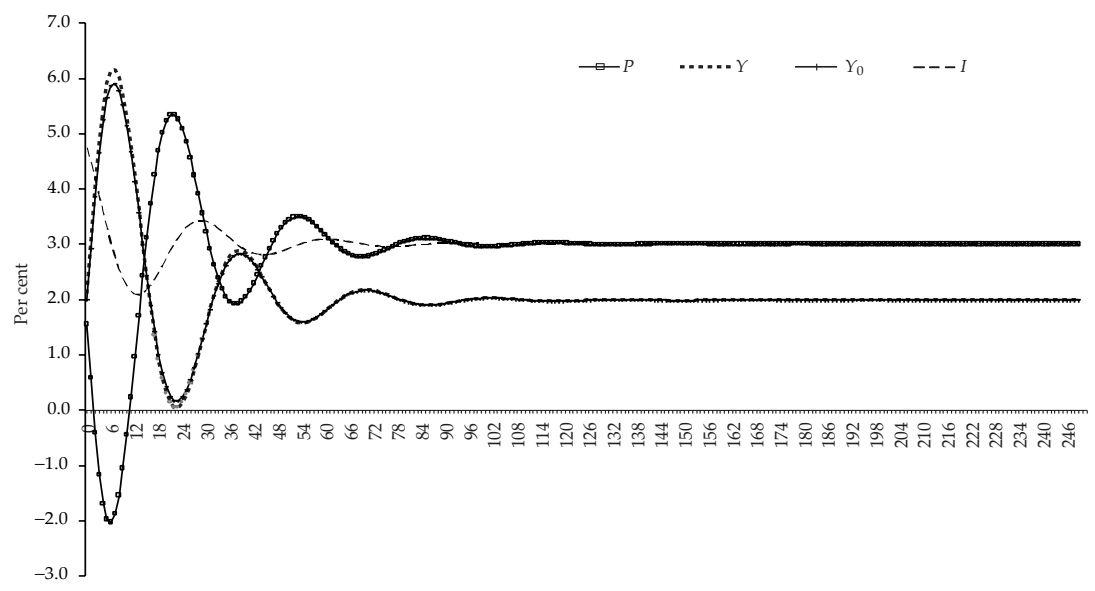

Where: $P$ is the rate of inflation, $Y$ is the growth rate of real output, $Y_{0}$ is the growth rate of productive capacity and $I$ is the short-run nominal interest rate.

\footnotetext{
${ }^{9}$ Holding constant all the parameters used in the last simulation.
} 
Figure 4 above shows that a reduction in the level of capital controls has no effect over the long-run equilibrium values of the selected variables. However, we can see a clear increase in the amplitude of oscillations of these variables around their equilibrium values when we compare this dynamics with the one shown in figure 3. From this reasoning we can conclude, in accordance with Ono, Silva, Oreiro and Paula (2005), that the degree of openness of the capital account is irrelevant for long-run growth. However, a decrease in the level of capital controls will result in greater macroeconomic instability.

As a last experiment we will evaluate the impact over the dynamics of the selected of an increase of the long-run target for inflation relative to the international inflation level. For such we will consider that the Central Bank increases the long-run inflation target from 3\% per year to $5 \%$ per year, holding constant all the parameter values of the last simulation. The effects of changes in the long-run inflation target can be shown in figure 5 .

As we can see in figure 5, an increase in the long-run inflation-target has a clear negative impact over the long-run equilibrium value of the growth rate of real output of the economy at hand. More specifically, the economy will converge towards a long-run growth rate of only $0.3 \%$ per year.

In sum, the numerical simulations of the theoretical model allowed us to conclude that:

- The adoption of policies that aim to increase income-elasticity of exports create a clear increase in the long-run growth rate of real output. So there is a case for industrial policies to promote long-run growth. Industrial policies must be directed towards sectors and firms that produce tradable goods with a high income-elasticity of exports.

- The degree of conservatism in the operation of monetary policy, expressed in the coefficient of interest-rate inertia, has no impact over long-run growth; but influences the amplitude of oscillations of the main macroeconomic variables around its longrun equilibrium values. More specifically, the higher the degree of conservatism of the Central Bank, the higher will be macroeconomic instability.

- Policies that aim to increase the level of openness of the capital account do not have any impact over the long-run growth rate of real output or over the long-run equilibrium value of nominal interest rates. However, these policies have the effect of increasing the instability of the main macroeconomic variables. 
FIGURE 5

Dynamics of the growth rate of real output and productive capacity, inflation and nominal interest rate assuming an increase in the income elasticity of exports, in the level of interest rate inertia, in the degree of openness of capital account (a decrease in the level of capital controls) and in the long-run inflation target

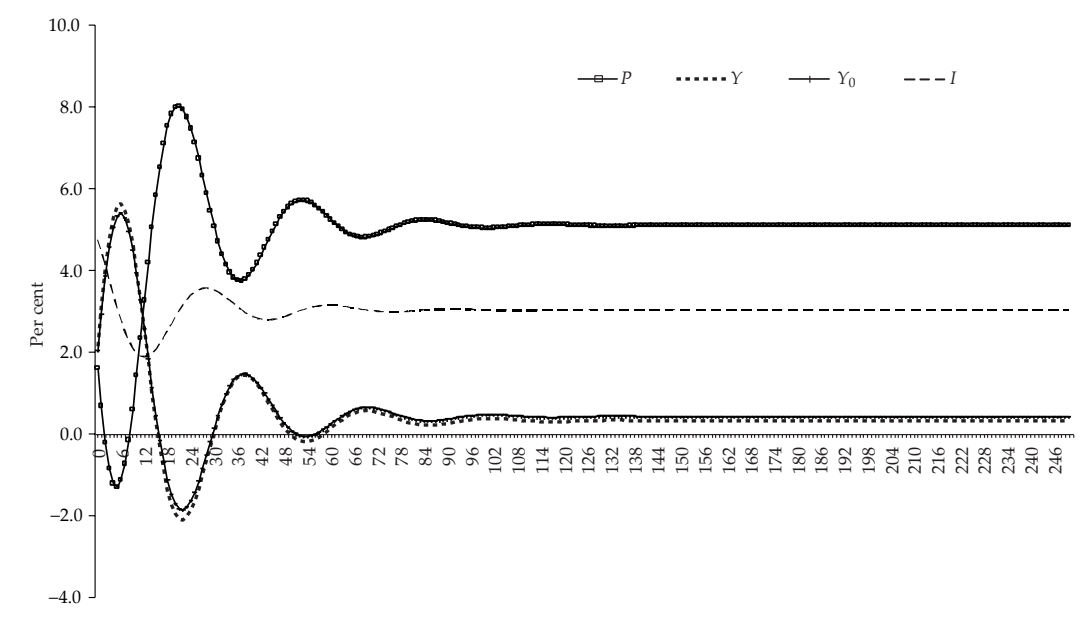

Where: $P$ is the rate of inflation, $Y$ is the growth rate of real output, $Y_{0}$ is the growth rate of productive capacity and $I$ is the short-run nominal interest rate.

\section{CONCLusions}

We have presented a modified Kaldorian model of cumulative causation in order to analyze the effects of policies that aim to change the degree of capital mobility and the rules of operation of monetary policy over longrun economic growth.

Regarding the steady-state solution of the model, we have concluded that: i) there is an inverse relation between the growth rate of real output and the rate of inflation, given the growth rate of world income and the international rate of inflation; ii) the convergence of the inflation rate to 
its long-run target requires that Central Bank has only one goal for monetary policy: to control inflation; and iii) a balanced growth path requires that Central Bank sets a long-run target for inflation that is flexible and adjustable to the conditions prevailing in the world economy. In particular, the long-run inflation target must be increased in periods of increasing levels of international interest rates and/or decreasing growth rates of the world economy.

Numerical simulations of the model at hand show not only that the model has a stable dynamics for a range of numerical values of the parameters but also show that: iv) the adoption of policies that aim to increase the income-elasticity of exports create a clear increase in the long-run growth rate of real output; so there is a case for industrial policies to promote long-run economic growth; v) the degree of conservatism in the operation of monetary policy, expressed in the coefficient of interest-rate inertia, has no impact over long-run growth; but influences the amplitude of oscillations of the main macroeconomic variables around its long-run equilibrium values; and vi) policies that aim to increase the level of openness of capital account do not have any impact over the long-run growth rate of real output or over the long-run equilibrium value of nominal interest rates; although these policies have the effect of increasing the instability of the main macroeconomic variables

\section{REFERENCES}

Arestis, P. and M. Sawyer, "Aggregate demand, conflict and capacity in the inflationary process", Cambridge Journal of Economics, vol. 29, no. 6, 2005, pp. 959-974.

- "The nature and role of monetary policy when money is endogenous", Cambridge Journal of Economics, vol. 30, no. 6, 2006, pp. 847-860.

Barbosa, F.H., "A inércia da taxa de juros na política monetária", Ensaios Econômicos, Rio de Janeiro, Fundação Getúlio Vargas, 2004.

Davidson, P., "Can, or should, a central bank inflation target?", Journal of Post Keynesian Economics, vol. 28, no. 4, 2006, pp. 689-703. 
Dixon, R.J. and A.P. Thirwall, "A model of regional growth-rate differences on Kaldorian lines", Oxford Economic Papers, vol. 27, no. 2, 1975, pp. 201-214.

Domar, E., "Capital expansion, rate of growth and employment", Econometrica, vol. 14, 1946, pp. 137-147.

Dosi, G., K. Pavitt and L. Soete, The Economics of Technical Change and International Trade, London, Macmillan Press, 1990.

Harrod, R., "An essay in dynamic theory", The Economic Journal, vol. 49, 1939, pp. 14-33.

Kaldor, N., "The role of effective demand in the short and long-run growth", in A. Barrére (org.), The Foundations of Keynesian Analysis, London, Macmillan Press, 1988.

Keynes, J.M., The General Theory of Employment, Interest and Money, London, Macmillan Press, 1936.

Ledesma, M.L. and A.P. Thirwall, "The endogeneity of the natural rate of growth", Cambridge Journal of Economics, vol. 26, no. 4, 2002, pp. 441-459.

Maddison, A., Historia del desarollo capitalista, Barcelona, Ariel, 1991.

Ono, F.H., G.J. Silva, J.L. Oreiro and L.F. Paula, "Conversibilidade da conta de capital, taxa de juros e crescimento econômico: uma avaliação da proposta de plena-conversibilidade do Real", Revista de Economia Contemporânea, vol. 9, no. 2, 2005, pp. 231-261.

Palley, T., "Pitfalls in the theory of growth: an application to the balance-ofpayments-constrained growth model", in M. Setterfield (ed.), The Economics of Demand-Led Growth, Aldershot, Edward Elgar, 2002.

_- "Monetary policy in an endogenous money economy", in P. Arestis and M. Saywer, A Handbook of Alternative Monetary Economics, Aldershot, Edward Elgar, 2006.

Robinson, J., Essays in the Theory of Economic Growth, London, Macmillan Press, 1962.

Setterfield, M., Rapid Growth and Relative Decline, London, Macmillan Press, 1997.

Solow, R., "Technical change and the aggregate production function", Review of Economics and Statistics, vol. 39, 1957, pp. 312-320. 